\title{
How Organisation, Job, Personal Factors, and Motivation Drive Job Performance and Technology Adoption
}

\author{
Hemalatha Somu* \\ Graduate School of Business \\ Universiti Sains Malaysia \\ Penang, Malaysia. \\ pkv7599@gmail.com \\ Jignyasu Prafulla Joshi \\ Graduate School of Business \\ Universiti Sains Malaysia \\ Penang, Malaysia. \\ jignyasu.joshi@gmail.com
}

\author{
Aizzat Mohd Nasurdin \\ School of Management \\ Universiti Sains Malaysia \\ Penang, Malaysia. \\ aizzat@usm.my \\ Lavinsa Paramasivan \\ Graduate School of Business \\ Universiti Sains Malaysia \\ Penang, Malaysia. \\ lavinsa@gmail.com
}

\author{
Cheng Ling Tan \\ Graduate School of Business \\ Universiti Sains Malaysia \\ Penang, Malaysia. \\ tanchengling@usm.my
}

\begin{abstract}
In recent years, Industry 4.0 has been introduced as a popular term to describe the trend towards digitization and automation of the manufacturing environment. To sustain in this new era with technology adoption, every engineer in manufacturing companies especially $R \& D$ engineers plays an important role in innovation, product design, and development. This article proposes organization, job, and personal factors and motivation to enhance the engineer performance. Researchers and practitioners have paid considerable attention to job performance because performance at an individual level has desirable consequences on an organization. However, studies on the role of motivation as a mediating in the relationship between the predictors and performance are relatively limited. From a strategic perspective, since organizations have a major influence on their human capital, incorporating organizational-level elements such as organization, job, and personal factors may facilitate our understanding of the interlocking relationships between the above factors and employee job performance. This paper aims to review the extant literature and propose a model linking organization (compensation), job (job autonomy) and personal (pro-active personality) factors with job performance. Also discussed is the electrical and electronics sector in the Malaysian manufacturing context to support the proposed linkage. Findings from the review were then utilized to develop a research model for further testing.
\end{abstract}

Keywords: compensation, job autonomy, job factor, job performance motivation, organisation factor, personal factor, pro-active personality

\section{INTRODUCTION}

Growing attention is being paid to the implications of integrating Internet of Things and Services (IoTS) technologies into industrial value creation. This new paradigm of digitized and connected manufacturing is referred to as "Industry 4.0" or "Industrial Internet of Things" (IIoT) and is transforming established manufacturing companies into smart and autonomous production in conjection with technology adoption [1]. Associated with this flexibility, Industry 4.0 aims at overcoming contemporary challenges, such as intensifying global competition, volatile markets and demands, required customization, as well as decreasing innovation and product life cycles. Industry 4.0 serves as a useful and targeted approach to deal with these challenging requirements [1,2]. In this context, the term Industry 4.0 comprises a variety of technologies to enable the development of a digital and automated manufacturing environment as well as the digitisation of the value chain [3]. This results in improvements in product quality and a decrease of time tomarket as well as improvements in companies' performance [4].

Rapid changes in today's business environment have necessitated the need for organisations to operate their activities strategically by operating on the lowest possible cost. To achieve better resource utilisation, these companies have been focusing on the reliability of their products or service delivery to meet customers' expectations. Many manufacturing companies have fought the global pressures of competition by becoming increasingly technologically advanced, moving up-market to produce more value-added products, and upgrading the skills of their workforce. The success of an organisation is always dependent upon its high-performing employees. Employees play a major role in implementing the business strategies developed by their top managers. Without employees, an organisation will face difficulties in executing its activities. Yet, some organisations are confronted with the problem of employees' performance.

\section{A. Background of Study}

Malaysia's manufacturing sector is one of the leading industries that have contributed to the growth of the country's economy, particularly in terms of manufacturing export, employment, and investment [5,6]. The manufacturing sector is the second highest key contributor to the Malaysian economy in 2016 and 2017. For example, in the year 2017/2018, within manufacturing industry the E\&E business proceeded as the main business at runner up as far as number of activities endorsed (RM9.7 billion), 
with total investment of RM58.6 billion, 92\% of total investments approved in this manufacturing sector [6].

Manufacturing organisations have been focusing on product design and innovation. However, the relative importance of those factors depends on the type of organization. Manufacturers have been focusing primarily on the advantage and quality of product innovation. Thus, the performance of $R \& D$ engineers plays an important role in product design and innovation of the manufacturing sector. A review of the extant literature indicates the following three specific factors under organization, job and personal factor: (i) Compensation, (ii) Job autonomy and (iii) Pro-active personality. These three predictors will be discussed further in the following subsection.

\section{B. Problem Statement}

Engineers have an innovative potential, but without proper organizational content, this potential may never be realized. In a global economy, a competitive advantage can diminish quickly because of increased competition and the rapid development of new technologies [6]. As stated in an article written by Y. Bhg. Dato' Wong Siew Hai, Chair of Malaysian American Electronics Industry (MAEI) 2013, one of the key challenges in today's E\&E manufacturing is the lack of experienced engineers. Yet, research on the job performance of the $\mathrm{R} \& \mathrm{D}$ engineers in the manufacturing sector in Malaysia is still limited, particularly studies that focus on organization, job and personal factors such as compensation, job autonomy, and pro-active personality. To compete with industry 4.0 and technology adoption R\&D engineers play a crucial role in innovation and design products with low cost without comprising the quality. Thus, the R\&D engineer job performance very important for the manufacturing companies towards digitization and automation in the current era industry 4.0.Therefore, the present study proposes to investigate how the factors influence the job performance of $R \& D$ engineers in the manufacturing sector in Malaysia.

In the digital transformational era, the need to develop innovative products or services has become more intense specifically in the E\&E industry where manufacturing efficiency and productivity are highly desirable. Because engineers form the backbone of an organization in the E\&E industry, their performance would have a significant impact on the organization's survival and success. In the fourth quarter of 2017, manufacturing was the second-highest key contributor to the Malaysian economy [7]. Manufacturing accounted for $82.1 \%$ of Malaysia's total exports in 2017, according to the Malaysian External Trade Development Corporation [8]. Although Malaysia's manufacturing sector is one of the key contributors to its economy, the country's manufacturing ranking in comparison to the country's economy, the country's manufacturing ranking is still far behind compared to other countries is still far behind. Based on the worldwide rankings using the Purchasing Manager's Index (PMI), as of May 2018, the manufacturing sector has been dominated by Europe, particularly Germany, followed by Austria, Netherlands, and the United Kingdom (Source: HIS Markit, JPMorgan, Nikkei, Caixin, May 2018). Of the 29 countries covered by the PMI survey in May 2018, a deterioration in manufacturing conditions was noted for four countries, one of which is Malaysia. The country's PMI index fell below 50.0, indicating a deterioration in manufacturing productivity when compared with other countries. This proves that the performance of the manufacturing sector in Malaysia is still lagging (Please refer to Fig. 1). This shortcoming may be attributed to the decline of manufacturing productivity. One avenue to address this shortcoming would be through improvements in job performance, particularly those of the $R \& D$ engineers' in the Malaysian manufacturing industry.

Given the above setting, there is an urgent need for the Malaysian manufacturing especially in E\&E industry to reenergise itself and become productive and advanced. This can be accomplished by looking into the organisation, job and personal factor such as compensation, job autonomy and pro-active personality. Furthermore, it has been widely acknowledged that employing a supportive organisation, job and personal factor can lead to improvements in employee's attitudes and behaviours. One form of work behaviour is job performance and motivation.

\section{Research Question}

Do organisation, job and personal factors like the dimensions of (compensation, job autonomy and pro-active personality) link job performance with motivation?

\section{Purpose of Study}

On the basis of the above-mentioned discussion, the purpose of this paper is to propose a model linking selected organisation, job and personal factor dimensions of (compensation, job autonomy and pro-active personality), with mediating motivation to enhance the job performance.

\section{MATERIALS AND METHODS}

\section{A. Literature Review}

\section{Organisation Factor (Compensation) and Job Performance}

At the organisational level, compensation is critical in attracting, retaining, and motivating employees to continue contributing towards an organisation's success [9]. The reason is that a compensation system is important to influence individuals' choices to work with an organisation. Many organisations use a compensation system not only as a reward and recognise employees' efforts and contributions but also as a motivation tool [10] to improve employees' productivity through improving job performance, impeding the intention to leave and increasing career satisfaction. Compensation systems have traditionally been designed to attract and retain employees and to motivate them to increase their effort and outputs toward the achievement of organisational goals [11]. A compensation system is also considered as one of the most significant costs of operating a business. A compensation system not only can influence hiring and retention decisions but is also an important tool for aligning employees' interest with organisational goals, particularly by designing and providing rewards for meeting specific goals assigned to them. The outcome of a compensation system has been widely studied and reported in the literature; or example, [12] found that salary growth 
and other non-salary benefits provided to employees have a significant influence on their intention to quit. [13] Found that employees' performance is significantly affected by the total compensation system. Several studies on productivity have found that high talent individuals often seek for high pay. Thus, if an organisation is able to offer an attractive compensation system for them, they might perform better in the job scope with the current organization $[14,15]$. On the contrary, an organisation's failure to provide equitable compensation would result in employees' negative attitudes toward the organisation such as enhance employee job performance with the current organisation. As such, it is proposed that:

Proposition 1: Compensation system will be positively related to job performance.

\section{Job Factor (Job Autonomy) and Job Performance}

Job autonomy provides resources, such as time and role management and decision-making authority, so that employees can effectively and efficiently manage both work and non-work aspects of their lives (i.e., decreased constraints).In their meta-analysis, Fried et al. [16] noted that job characteristics were correlated to behavioural outcomes such as productivity, job involvement and job performance. Furthermore, empirical evidences have also confirmed that autonomy, feedback, skill variety, task identity and task significance have a positive and significant relationship with job performance and commitment [Goodlin]. When employees' job satisfaction is high, their motivation is expected to be high [17]. The job characteristics model developed by Hackman and Oldham [17] points that the existence of five core job dimensions will lead to feelings of meaningfulness, independence and results-oriented, all of which will increase job performance. As such, it is proposed that:

Proposition 2: Job autonomy will be positively related to job performance.

\section{Personal Factor (Pro-active Personality) and Job Performance}

Bateman and Crant [18] discovered that proactive personality in any organization was favourably associated with staff, and the degree of positive environmental change revealed most important private accomplishments. Crant and Bateman [19] also discovered that pro-active personality was predictive of job performance. Individuals with a greater proactive personality are more likely to take action to impact their environment, seek possibilities to enhance their circumstances, and generate circumstances for improving their social context than those with a reduced proactive personality. Researchers have proved a positive relationship between proactive personality and a range of organizational results, including management [20,18], team performance, socialization and organizational entry, career achievement, and job performance [19]. Despite its significance, the mechanisms through which proactive personality contributes to beneficial job-related results have been directly examined by a few research. Because proactive personality is a structure of personality, it is likely to be a distal predictor of the work behaviours of staff [21]. Therefore, prospective mediating factors that connect proactive personality to performance need to be examined.
Proactive staff approach their employment and careers differently from those of less proactive individuals. Proactive workers select and create situations that increase the likelihood of high job performance levels [19]. They may be even more likely to identify and pursue selfimprovement opportunities, such as acquiring additional education or skills needed for future promotions. Instead of creating them, less proactive individuals respond to their environment and retain the status quo [21]. As such, it is suggested the hypothesis as below:

Proposition 3: Pro-active personality will be positively related to job performance.

\section{Organisation Factor (Compensation) and Motivation}

Compensation under [22] is all the income in the form of money, directly or indirectly goods received by employees as a reward for services rendered to the company. The amount of compensation reflects the status, recognition and the level of needs fulfilment received by employees with family. The greater the remuneration received by the employee means higher position, better status and more needs fulfilment. Compensation is an award or rewards for workers who have contributed in achieving objectives through the activities of the so-called work [23].

Compensation is important for employees as individuals because the amount of compensation reflect the value of the employees among other employees themselves, their families and communities. When employees saw their compensation is inadequate, their performance, work culture and level of motivation could drop drastically [24]. If the system of compensation awarded by the organization is fair enough for the employees, it will encourage employee to perform better with their work and more responsible for each task given. The purpose of compensation is to appreciate the achievements of employee, ensures fairness and compensation systems must be able to motivate the employees. Therefore, compensation is an important factor to be able to work better and more productively, also to motivate someone to work. Not only should the compensation factor be considered by the organization in order to improve employee performance, but also the motivation factor. Motivation is a factor that encourages a person to perform a specific activity; hence the motivation is often interpreted as a factor that drives behaviour. Thus, proposed that:

\section{Proposition 4: Compensation will be positively related to motivation.}

\section{Job Factor (Job Autonomy) and Motivation}

Job autonomy also seems to enhance motivation, and therefore performance. Job autonomy refers to an individual's perception of having some form of control over the environment. This sense of control is thought of as a psychological need because it makes us feel like an environment or situation is part of our own doing [25]. As a result, autonomy can enhance motivation, establish a sense of satisfaction, and improve an individual's sense of competence. Job autonomy can also lead to physiological and subjective well-being by increasing energy [25]. Research shows that subjective well-being based on happiness/enjoyment is heavily influenced by perceived job autonomy during various contexts. Greater autonomy to 

assessments in academic settings are related to greater perceived happiness, enjoyment, and well-being [26]. More job autonomy from individuals' social support systems is also associated with happiness [27]. Various degrees of autonomy can directly enhance motivation [Eitam]. When individuals are given the option to control whether or not they want to be told how they performed in various tasks (like physical and computerized lab tasks), they were more motivated to perform well because, to some extent, the task became a part of their own doing [28]. This job autonomy manipulation also appears to enhance motor learning, like learning how to throw with one's non-dominant hand and throwing a beanbag at a target with more accuracy [29]. Thus, proposed that:

\section{Proposition 5: Job autonomy will be positively related to} motivation.

\section{Personal Factor (Pro-active Personality) and Motivation}

Proactive personality, a stable personal characteristic, measures the extent to which an individual is relatively unconstrained by situational forces and the degree to which there are environmental changes [18]. In most situations, proactive personalities will scan for opportunities, show initiatives, take actions, and preserve meaningful changes [19]. A recent study found that job stress developed selfefficacy (i.e, with regard to capturing their perceived capability) in individuals with high proactive personality [30]. In such a situation, it is posited that proactive employees are more able to create environments conducive to their overall performance and creativity [31] and their motivation to work. Even when proactive employees are unhappy with their jobs, they may have greater self-esteem [32] and self-efficacy and personality-driven motivation related to carrying out a broader and more proactive set of work responsibilities. They may also have better learning motivation and creativity. Thus, proposed that:

Proposition 6: Pro-active Personality will be positively related to motivation.

\section{Motivation and Job Performance}

Motivation refers to the intrinsic and extrinsic elements that influence an individual to act in certain ways or take certain actions [33]. Motivation is a force (either intrinsic or extrinsic) that makes people do what they do. This means individual motivation is influenced by both internal factors (including personal needs and expectations) and external factors (organizational reward and compensation). According to [34], while employees' job performance is the function of cognitive ability at transition stages, dispositional and motivational factors inherent in the job would be stronger predictors of job performance at maintenance stages. According to Self-Determination Theory $[8,21]$, when an individual is intrinsically motivated, he or she performs some act because it is intrinsically gratifying. For example, an intrinsically motivated employee will perform his or her job, at least in part, because the work is experienced as being interesting and enjoyable. When an individual is extrinsically motivated, he or she performs some act because it has some instrumental value. For example, an extrinsically motivated employee will perform his or her job, at least in part, because the work is a means of obtaining an income.
Several research studies have determined that the
crease in job performance can be caused by a lack of motivation [16]. Motivation is quickly becoming an important and highly researched topic in the organizational behaviour area [35]. The reason is clear: motivation refers to the degree to which an individual experience, positive internal feelings when performing job effectively. The concept therefore should substantially relate to an employee's actual job performance. In other words, an individual experiencing high motivation should perform at high levels, because by doing he or she is receiving many personally valued rewards. Lack of motivation may turn into a chronic condition whereby employees continuously give more than they receive in return, eventually depleting employees' energy resources and, lack of performance and, hence, fostering stress and burnout. Therefore, it is likely that the nature of the organization, job and personal factors relationship between job performances via will be affected by motivation. The relationship is likely to be stronger with high motivation. The foregoing discussion has prompted the following proposition:

Proposition 7: Motivation will be positively related to job performance.

\section{B. Research Methods}

This research was grounded on a solid theoretical framework that combines secondary data. A systematic literature review was conducted using as archival method to review the articles related to organization (compensation),job (job autonomy) and personal (pro-active personality) factors, motivation, and job performance as cited in database such as Emerald, ProQuest and Science Direct. The secondary data were analysed to construct a solid theoretical structure as the foundation for this study.Past literature was looked into it for archival method.

\section{Conceptual Framework}

Based on the preceding discussion, a conceptual framework is proposed as depicted in Fig. 2. Organization, job and personal factors are assumed to predict job performance within the context of the operators in manufacturing sector. Job performance, for this study, focuses on task performance with mediating role as motivation.

\section{Results}

As discussed in the literature review, this study proposes an integrated framework (Fig. 2), which highlights the organization, job and personal factors as the independent variables and, job performance as the dependent variable. Motivation acts as the moderator.

\section{DISCUSSION AND CONCLUSION}

The present paper discusses the importance of motivation and job performance and how the three specific organization (compensation), job (job autonomy) and personal (pro-active personality) factors can help employees, particularly in the manufacturing $R \& D$ engineers, to become highly motivated in their work and deliver higher job performance. Findings that facilitated the development of the model were derived from the review of secondary information through a library search engine. The 
paper provides some practical insights on the use of selected organization, job and personal factors in influencing job performance. Because motivation is important in strengthening the organization, job and personal performance relationships, we suggest that manufacturing forms strive to constantly motivate their current employees apart from placing emphasis on recruiting highly motivated candidates. Highly motivated and high-performing workers represent a key source of competitive advantage for an organization. Given the intense challenges faced by the manufacturing sector globally and more so in Malaysia, there is an urgent need for Malaysian manufacturing firms to stimulate their workforce to become highly motivated and high performers.

\section{REFERENCES}

[1] J. M. Müller, D. Kiel, and K. I. Voigt, "What drives the implementation of Industry 4.0? The role of opportunities and challenges in the context of sustainability," Sustainability, vol. 10(1), pp. 247, 2018

[2] D. Kiel, J. Müller, C. Arnold, and K. I. Voigt, "Sustainable Industrial Value Creation: Benefits and Challenges of Industry 4.0," Int. J. Innov. Manag, vol. 21, 2017

[3] T. D. Oesterreich and F. Teuteberg, "Understanding the implications of digitisation and automation in the context of Industry 4.0: A triangulation approach and elements of a research agenda for the construction industry," Computers in industry, vol. 83, pp. 121-139, 2016

[4] M. Brettel, N. Friederichsen, M. Keller, and M. Rosenberg, "How Virtualization, Decentralization and Network Building Change the Manufacturing Landscape: An Industry 4.0 Perspective," Int. J. Mech. Aerosp. Ind. Mechatron. Manuf. Eng., vol. 8, no. 1, 2014.

[5] T. Brandt, S.W. Chuah, "Market watch 2012: Electrical and Electronic Industry in Malaysia," Conference Paper in Important Malaysian Electrical and Electronic Trade Fairs 2012, Penang International Sports Arena(PISA), Malaysia. Available from: http:// www.malaysia.ahk.de/fileadmin/ahk_malaysia/Market_reports/

[6] MIDA [Malaysian Investment Development Authority]. Industries in Malaysia:Electrical and electronics industry. Available from: http://www.mida.gov.my/env3/ index.php? Page=ee [Accessed 2019]

[7] Department of Statistics Malaysia. Index of Industrial Production

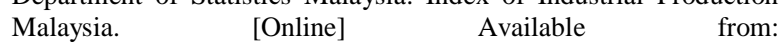
http://www.statistics.gov.my/eng/index.php?option=com_content\&v iew=article $\& i d=268$ :index-of-industrial-production-malaysia-july$2008 \&$ catid=43:index-of-industrial-production-malaysia\&Itemid=12 [Accessed 28 January 2008]

[8] Malaysia Productivity Corporation report, (2010) (MATRADE).

[9] L. Phillips, and M. A. Fox, "Compensation strategy in transnational corporations," Management Decision, vol. 41, pp. 465-476, 2003

[10] R. K. Chiu, V. Wai-Mei Luk, and T. Li-Ping Tang, "Retaining and motivating employees: Compensation preferences in Hong Kong and China," Personnel Review, vol. 31(4), pp. 402-431, 2002

[11] T. J. Bergmannand V. G. Scarpello, Compensation Decision Making (4 th), Mason: Cengage Learning, 2001

[12] C. O. Trevor, B, Gerhart, and J. W. Boudreau, "Voluntary turnover and job performance: Curvilinearity and the moderating influences of salary growth and promotions," Journal of applied psychology, vol. 82(1), pp. 44, 1997

[13] J. G. Miller and K. G. Wheeler, "Unraveling the mysteries of gender differences in intentions to leave the organization," Journal of Organizational Behavior, vol. 13(5), pp. 465-478, 1992

[14] J. L. Shepherd and B. P. Mathews, "Employee commitment: academic vs practitioner perspectives," Employee relations, vol. 22(6), pp. 555-575, 2000
[15] E. Jardine and S. Amig, "Managing human capital. Behavioral Health Management," vol. 21(2), pp. 22-26, 2001

[16] Y. Fried, A. Shirom, S. Gilboa, and C. L. Cooper, "The mediating effects of job satisfaction and propensity to leave on role stress-job performance relationships: Combining meta-analysis and structural equation modeling," International Journal of Stress Management, vol. 15(4), pp. 305, 2008

[17] J. R. Hackman and G. R. Oldham, Work redesign, 1980

[18] T. S. Bateman and J. M. Crant, "The proactive component of organizational behavior: A measure and correlates," Journal of organizational behavior, vol. 14(2), pp. 103-118, 1993

[19] J. M. Crant and T. S. Bateman, "Charismatic leadership viewed from above: The impact of proactive personality," Journal of organizational Behavior, vol. 21(1), pp. 63-75, 2000

[20] J. M. Crant, "Proactive behavior in organizations," Journal of management, vol. 26(3), pp. 435-462, 2000

[21] C. A. Clark, T. R. Barrick, M. M. Murphy, and B. A. Bell, "White matter fiber tracking in patients with space-occupying lesions of the brain: a new technique for neurosurgical planning?" Neuroimage, vol. 20(3), pp. 1601-1608, 2003

[22] Hasibuan and S. P. Malayu, Human Resource Management, Jakarta: Bumi Aksara, 2007

[23] Nawawi and Hadari, Human Resource Management for Competitive Business, Yogyakarta: Gadjah Mada University Press, 2005

[24] Robbins and P. Stephen, Organizational behavior, Jakarta: Penerbit Salemba Empat, 2006

[25] E. L. Deci and R. M. Ryan, "Self-determination theory: A macrotheory of human motivation, development, and health," Canadian psychology/Psychologie canadienne, vol. 49(3), pp. 182, 2008

[26] S. O'Donnell, K. Chang, and K. Miller, "Relations among autonomy, attribution style, and happiness in college students," College Student Journal, vol. 47(1), pp. 228-234, 2013

[27] M. Demir, M. Özdemir, and K. P. Marum, "Perceived autonomy support, friendship maintenance, and happiness," The Journal of psychology, vol. 145(6), pp. 537-571, 2011

[28] C. M. Janelle, D. A. Barba, S. G. Frehlich, L. K. Tennant, and J. H. Cauraugh, "Maximizing performance feedback effectiveness through videotape replay and a self-controlled learning environment," Research Quarterly for Exercise and Sport, vol. 68(4), pp.269-279, 1997

[29] J. T. Patterson and T. D. Lee, "Self-regulated frequency of augmented information in skill learning," Canadian Journal of Experimental Psychology/Revue canadienne de psychologie expérimentale, vol. 64(1), pp. 33, 2010

[30] Y. Liu, N. Lv. J. Kang, Z. Zhou, Q. Zhao, L. Ma, L., ... and L. Nie, "Deep photoacoustic/luminescence/magnetic resonance multimodal imaging in living subjects using high - efficiency upconversion nanocomposites," Advanced Materials, vol. 28(30), pp. 6411-6419, 2016

[31] Y. Gong, S. Y. Cheung, M. Wang, and J. C. Huang, "Unfolding the proactive process for creativity: Integration of the employee proactivity, information exchange, and psychological safety perspectives," Journal of management, vol. 38(5), pp. 1611-1633, 2012

[32] S. Liao, Y. Hu, X. Zhu, and S. Z. Li, "Person re-identification by local maximal occurrence representation and metric learning," In Proceedings of the IEEE conference on computer vision and pattern recognition (pp. 2197-2206), 2015

[33] A. Nahavandi, R. B. Denhardt, J. V. Denhardt, and M. P. Aristigueta, Organizational behavior, California: Sage Publications, 2013

[34] K. M. Murphy, A. Shleifer, and R. W. Vishny, "Industrialization and the big push," Journal of political economy, vol. 97(5), pp. 10031026, 1989

[35] J. R. Hackman and G. R. Oldham, "Development of the job diagnostic survey," Journal of Applied Psychology, vol. 60(2), pp. 159,1975 


\section{APPENDIX}

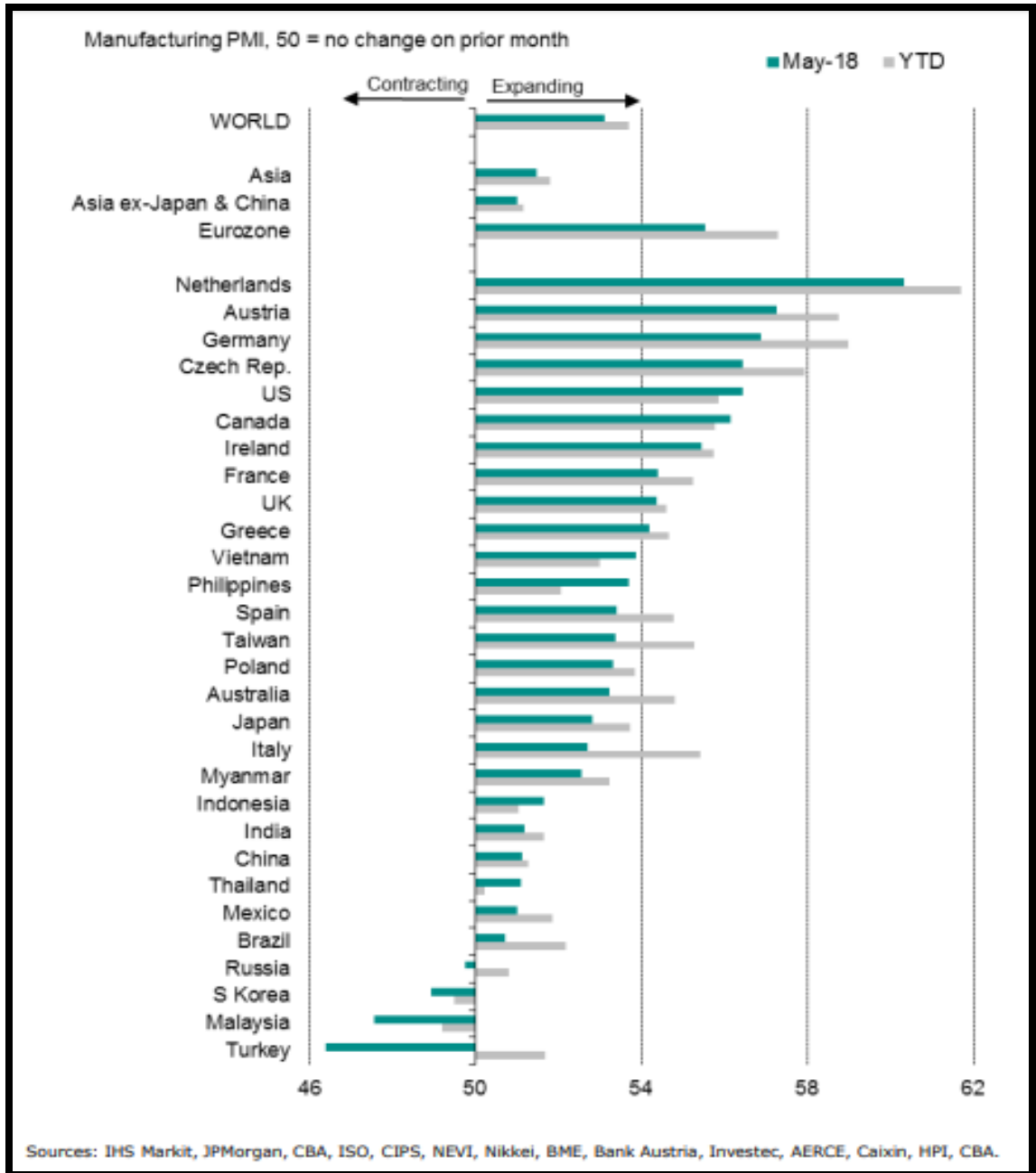

Fig. 1 Worldwide manufacturing PMI rankings, 2018 Source:HIS Markit, JPMorgan, Nikkei, Caixin,May 2018

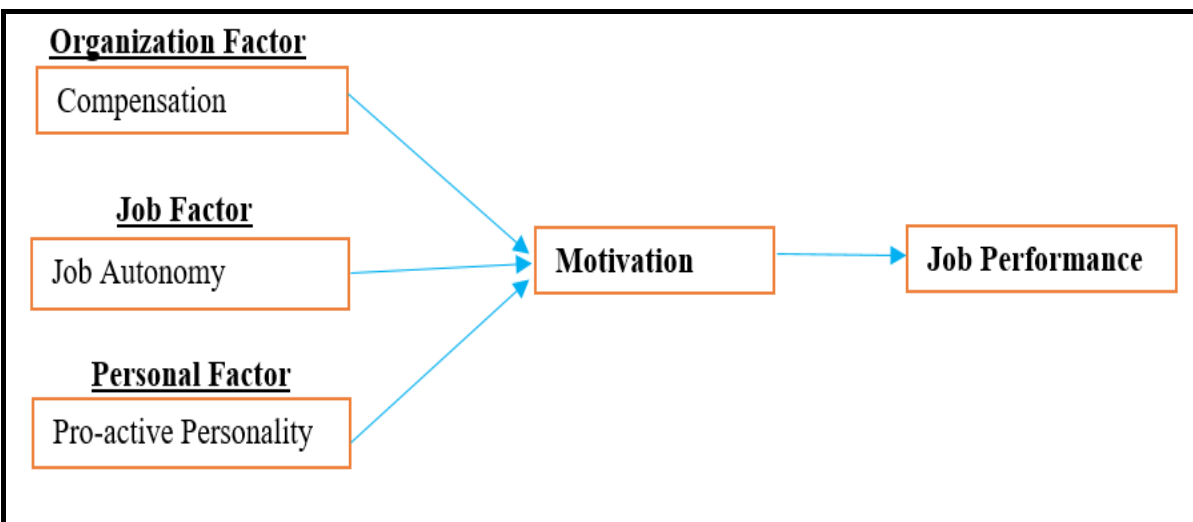

Fig. 2 Conceptual Framework 